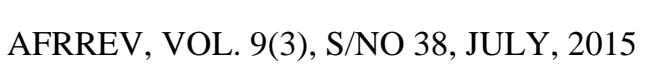 \\ African Research Review
}

An International Multidisciplinary Journal, Ethiopia

Vol. 9(3), Serial No. 38, July, 2015:75-87

ISSN 1994-9057 (Print) ISSN 2070-0083 (Online)

DOI: http://dx.doi.org/10.4314/afrrev.v9i3.7

\section{Building Social Justice among Academic Staffs of Tertiary Institutions, the Influence of Acculturation, Networking and School Management Support}

Ogunboyede, M. O.

Department of Educational Foundations and Counselling

School of Education

Adeyemi College of Education

E-mail:mikeboyede@yahoo.com

\&

Agokei, R. C.

Department of Educational Foundations and Counselling

School of Education

Adeyemi College of Education

E-mail:agokeialexander@yahoo.com

\begin{abstract}
The study investigated the influence of acculturation, networking and school management support on social justice building among university academic staffs of tertiary institutions. A descriptive survey research design was adopted for the study. The sample for the study was three hundred (300) randomly selected academic staffs of tertiary institutions in Oyo state. Four standardized instruments were used to collect data from the participants. Three research questions were raised and answered. Data collected were analyzed using multiple regression and Pearson Product Moment Correlation. The result indicated that acculturation, networking and school

Copyright (C) IAARR, 2015: www.afrrevjo.net Indexed African Journals Online: www.ajol.info
\end{abstract}


management support, all had significant relationships with social justice building of university academic staffs. The combined effect of the three variables was significant and produced an $\mathrm{F}$ - ratio value significant at 0.05 level $(\mathrm{F}=10.8241 ;<.05)$. The three variables accounted for $30.9 \%$ of the total variance on social justice building of the participants with acculturation being the most potent predictor in the investigation. Based on the findings recommendations were made for all significant stakeholders.

Key words: Acculturation, Networking, School management support, Social justice

\section{Introduction}

A review of current educational research literature reveals a number of problematic features on the broad topic of education for diversity, equity, and social justice. A growing number of education reformers, policymakers, and researchers have argued that many of the well-publicized and pivotal causes and shortcomings of the tertiary education system in Nigeria are, to a significant extent, due to inadequacies in the working conditions, resources, and support afforded to schoolteachers. Proponents of this view hold, for example, that teachers are underpaid, have too little to say in the operation of schools, are afforded too few opportunities to improve their teaching skills, suffer from a lack of support or assistance, and are not adequately rewarded or recognized for their efforts. These critics claim that the key to improving the quality of schools lies in upgrading the status, training, and working conditions of teaching, that is, in furthering the professionalization of teachers and teaching revolving in social justice. The rationale underlying this view is that upgrading the social justice teaching occupation could lead to improvements in teachers' performance, which will ultimately lead to improvements in student learning (Talbert \& McLaughlin 1993).

The phenomenon social injustice anchors predominantly in cultural, historical, economical, social, political, and ideological dimensions. There are two clear and distinct theoretical approaches to social justice discourses. One is a deductive approach that employs an ideal concept of justice. The other is an inductive approach that begins with socially unjust realities. The former is referred to as logocentric approach and the latter as grounded approach. The grounded approach begins with an ideal concept of social justice and then applies it to the socially unjust reality in a procedural way (Ekanga, 2005; Alexander, 2005). The grounded approach focuses on concrete examples of social injustice and aims for a socially just world by challenging social structure and institutional injustices (Collins, 1998; Wade, 2007). According to the grounded theorists, the necessity of teaching for social justice emerges from historical and current examples of social injustices (Tyson \& Park, 2006, 2008). Due to the uncompromisable approaches of social justice discourses, the 
task of defining social justice is a "formidable challenge" (Wade, 2007). The construct is observed to be full of complexity and frequently contradictory.

Inadvertently, researchers and educators are inevitably engaged in a cacophony of onto-epistemological issues when they deal with social justice issues. In other words, they examine epistemological orientation to social justice in an ontologically unjust world. Accordingly, social justice has been examined in its relation to dehumanization, oppression, and domination (Adams, Blumenfeld, Castandeda, Hackman, Peters \& Zuniga, 2000). For example, feminist researchers conduct research for the purpose of correcting the invisibility and distortion of female experience in an already gendered society (Lather, 2004). Researchers reveal through social justice studies that race/racism is a central form of oppression (Delgado \& Stefancic, 2001) Socio-economic status reproduces the hierarchical structure and consolidates the status quo (Wirt, Choy, Rooney, Sen \& Tobin, 2005) masculinity constrains on femininity (Collins, 1998; Olsen, 2000). In these studies, experiential knowledge of social injustice is privilege because it is legitimate, appropriate, and critical to understanding social injustice (Solorzano \& Delgado Bernal, 2001). Empathic knowledge is also important because it is a way of seeing through and beyond experiences of social injustice.

Teaching is a complex and demanding profession. In addition teaching for social justice is a political and moral project. It aims for a necessary deconstructive reversal and a constructive moral formation. The deconstruction of social injustice and construction of social justice are inseparable projects. The possibility of social justice is increased by what Bigelow, Christensen, Karp, Miner \& Peterson (2000) calls "a rainbow of resistance." In the process of permanent liberation, there is a call for the coalition of all people (Freire, 2003). With this, it becomes widely recognized that the role of the teacher has intensified, and teachers need to adapt to bureaucratically driven escalation of pressures, expectations and controls concerning what teachers do and how much they should be doing within the teaching day. The expectation on teachers to respond to current initiatives influences their professional lives in a number of ways. Further, there is an increasing body of research on social justice education (Bigelow \& Peterson, 2002; Tyson, 2002; Wade, 2004; Gutstein \& Peterson, 2005). However, it is important to note that few researchers conduct research on predictors of social justice building among teachers, and how it is related to their pedagogical practices. This study explores the relative effects of acculturation, social networking and school management support.

Acculturation can be referred to as a complex process whereby a minority group, as a result of continuous exposure to a cultural system which is significantly different from their original, cultural system modifies its social norms, attitudes, values and behaviors while relinquishing or retain the characteristics of their culture 
of origin. The multiethnic and diverse cultural background of individuals and their continual migration to other settings and culture contributes to the prospect to acculturation. Acculturation theory has historically focused on individual and group level changes in behavior, attitudes, and values that occur in response to a new cultural environment (Kim \& Abreu, 2001). Researchers have suggested that individuals respond and react to their new cultural environment, but mechanisms to explain individuals understanding and integration of their experiences have not been sufficiently advanced (Padilla \& Perez, 2003). A recent model emphasizes the active role that individuals take in creating changes in their cultural orientation (Padilla \& Perez, 2003). Without an individually-based assessment of acculturation levels, there is a danger that discussion and analyses regarding immigrants will overlook the important issue of variability within the minority population under consideration (Ridley, Li \& Hill, 1998). In several studies acculturation has emerged as an important predictor of various health outcomes under study (Balcazar, Peterson. \& Krull,1997; Yi, 1998; Kennedy, 2000).These type of research has been regarded as a step forward in the study of cultural influences, as it increases specificity in measuring cultural influences (Betancourt \& Regeser, 1993).

Literature suggest that networking behaviors, such as going for out for drinks to discuss business matters informally, attending conferences, or staying in contact with former colleagues, are essential to success in careers (Nierenberg, 2002; Torres, 2005). The current research defines networking by behaviors that are aimed at building, maintaining, and using informal relationships that possess the (potential) benefit to facilitate work related activities of individuals by voluntarily granting access to resources and maximizing common advantages (Wolff \& Moser, 2006; Forret \& Dougherty, 2004). The construct is defined on a behavioral level (Witt, 2004) and can be considered a "behavior syndrome" (Frese, Fay, Hilburger, Leng, \& Tag, 1997), that is, a set of interrelated behaviors that are consistently shown by individuals. Networking is also associated with favorable performance ratings (Sturges, Conway, Guest, \& Liefhooghe, 2005; Thompson, 2005) and may be a viable strategy in the work place (Wanberg, Kanfer, \& Banas, 2000). Networking behaviors are used to build and maintain informal contacts that enhance career success (Forret \& Dougherty, 2004). It could therefore hold promises for social justice building.

Further, promoting a positive school management support could be one way of fostering social justice building among academic staffs on tertiary institutions. A supportive school climate is the most important step in ensuring that schools provide a good basic values positive learning environment for all staffs and students. Basic values have predictive and explanatory potential, both at the individual and societal levels. Moreover, values can reflect major social change in societies and across nations. And values may influence the direction of social change and its speed 
(Davidov, Schmidt, \& Schwartz, 2008). According to Bell (1997), social justice education as a process is democratic and participatory, inclusive and affirming of human agency and human capacities for working collaboratively to create change. Social justice education as a goal gives "full and equal participation of all groups in a society that is mutually shaped to meet their needs. Hence, this study would be beneficial to all spheres of educational stakeholders and could obviously provoke other researchers into organizational effect on social justice building of teachers.

\section{Research questions}

The following research questions were raised in this study

1. Is there any significant relationship between acculturation, networking, school management support and social justice building among academic staffs of tertiary institutions?

2. What is the predictive effect of acculturation, networking and school management on social justice building among academic staffs of tertiary institutions?

3. What is the contributive effect of acculturation, networking and school management to social justice building among academic staffs of tertiary institutions?

\section{Research Design}

This study adopted a descriptive survey design of ex-post facto type. A survey study usually deals with the description and analysis of status of an area. It attempts to describe what exists now and explain why certain situations exist as well as focuses on the characteristics of the population by studying representative sample. It is in this accordance, that this study is adopting the survey study design to enable an effective investigation of the variables in this study without manipulating the variables as they naturally occurs.

\section{Population}

The population for the study consists of all academic staffs of tertiary institutions in Oyo state, Nigeria. This includes all States and Federal Universities, Polytechnics and Colleges of education within the state. Private institutions were excluded from this study on the bases of the differences and practices between private and public institutions.

\section{Sample and Sampling Technique}

A sample of three hundred (300) academic staffs of tertiary institutions in the designated area was randomly selected for the study. This was drawn from the State and Federal University, Polytechnic and College of Education within the state. One hundred (100) each were selected from the University, Polytechnic and College of 
Education resulting in the sampled three (300) hundred. The participants were aged between 35 and 56 years with a mean age of 47.2 years and a standard deviation of 11.23 .

\section{Instrumentation}

The research tool used for the study was a questionnaire which consists of an introductory letter and four sections (sections A, B, C, and D). Section A consists of attributive data such as name of institution, status, designation and gender. Section B, $\mathrm{C}, \mathrm{D}$ and $\mathrm{E}$ consist of standardized instruments measuring the independent variables and the criterion measure.

Section B Acculturation scale: The researcher adopted the Vancouver Index Acculturation (VIA) developed by Ryder, et al. (2000). The VIA is a 20-item instrument with separate measures for heritage and mainstream acculturation dimensions. Previous research has shown this instrument to have acceptable reliability. In this study, the reliability measures were found to be .84 for the heritage dimension and .82 for the mainstream dimension.

Section C: Networking behaviour Scale: The tool used as a measure was a self developed Networking behaviour scale. The scale is a 10-item scale patterned in a 5point likert format. The response pattern ranges from $1=$ never, $2=$ seldom, $3=$ often, $4=$ very often and $5=$ always. Typical item in the scale is "how often are you connected to the career world", "how often do you attend conferences, workshops and symposium on career search. Increasing scores indicates less difficulty with networking while decreasing scores indicates difficulty with networking. The scale has reported a split half-coefficient alpha of .75.

Section D: School Management support: The School Management Scale is a simple standardized questionnaire developed by Smith, Jim McCall and Louise Stoll (1997) in which the teaching staff population of a school is asked to rate 17 items on a 5point scale. The instructions are to put a score of 1 to 5 against each of the 17 items: the scoring hence ranges from $1=$ Strongly disagree, $2=$ Disagree, $3=$ Uncertain, $4=$ Agree, $5=$ Strongly agree.

Section E: Social justice building: The tool used as a measure was a self developed social justice building scale. The scale is a 10 -item scale patterned in a 5-point likert format. The response pattern ranges from $1=$ never, $2=$ seldom, $3=$ often, $4=$ very often and 5=always. Typical item in the scale is "I have faced challenges in teaching for social justice", "Positive teaching makes a social justice educator." Increasing scores indicates less difficulty with social justice building while decreasing scores indicates high difficulty with social justice building. 


\section{Procedure}

The researchers personally distributed and collected the completed questionnaire from the selected academic staffs of tertiary institutions. Participants were adequately informed of the confidentiality of the data provided and the need to be precise and truthful in filling the questionnaire. The questionnaire was then filled and returned by the participants after adequate understanding.

\section{Method of Data analysis}

Relationship between the independent variables and the criterion measure were analyzed using Pearson product moment correlation. The combine and relative effect of the independent variables to social justice building were further analyzed with multiple regression statistics.

\section{Results}

Table 1: Descriptive Statistics and Correlations among Variables

\begin{tabular}{lcccccccc}
\hline Variables & $\mathrm{N}$ & $\mathrm{X}$ & $\mathrm{SD}$ & 1 & 2 & 3 & 4 & 6 \\
\hline Social justice & 300 & 34.17 & 12.67 & 1.00 & & & \\
Acculturation & 300 & 88.92 & 7.66 & .428 & 1.00 & & \\
Networking & 300 & 32.21 & 10.98 & .411 & .367 & 1.00 & \\
$\begin{array}{l}\text { School management } \\
\text { support }\end{array}$ & 300 & 62.49 & 9.63 & .318 & .245 & .202 & 1.00 \\
\hline
\end{tabular}

From the table the correlation coefficients between all the variables were significant with the strongest relationship between social justice and acculturation.

Table 2: Summary of Regression Analysis between Predictor Variables and Social Justice

\begin{tabular}{|c|c|c|c|c|c|c|}
\hline $\begin{array}{l}\mathrm{R} \\
\mathrm{R}^{2} \\
\text { ADJ R }{ }^{2} \\
\text { STD. ERR }\end{array}$ & EST & $\begin{array}{l}=.561 \\
=.315 \\
=.309 \\
\text { IMATE }\end{array}$ & & & & \\
\hline $\begin{array}{l}\text { Source } \\
\text { Variation }\end{array}$ & Of & Df & Sum of Squares & $\begin{array}{l}\text { Means } \\
\text { Squares }\end{array}$ & F- Ratio & $\mathrm{P}$ \\
\hline Regression & & 3 & 4244.71 & 1414.90 & 104.96 & .000 \\
\hline Residual & & 296 & 3988.72 & 13.48 & & \\
\hline Total & & 299 & 8233.43 & & & \\
\hline
\end{tabular}


From the results presented in table 2 , the independent variables collectively yielded a coefficient of multiple regressions $(\mathrm{R})$ of .561 and an adjusted $\mathrm{R}^{2}$ of .315 and an adjusted $\mathrm{R}^{2}$ of .309 . This shows that $30.9 \%$ of the total variance of social justice building institutions by the participants is accounted for by the combination of the three predictive variables studied. The table as well indicates that the analysis of variance of multiple regression data produced an $\mathrm{F}$ - ratio value significant at 0.05 level $(\mathrm{F}=104.96 ; \mathrm{p}<.05)$. The findings thus confirm that the three variables are significant predictors of the criterion measure and that this prediction could not be by chance.

Table 3: Relative contribution of the Independent Variables to the Prediction of Social Justice

\begin{tabular}{llllll}
\hline & $\begin{array}{l}\text { Unstandardized } \\
\text { coefficient }\end{array}$ & & $\begin{array}{l}\text { Standardized } \\
\text { coefficient }\end{array}$ & T- Ratio & Sig \\
Predictor & $\mathrm{B}$ & SEB & BETA $\beta$ & & \\
\hline Acculturation & .221 & .048 & .286 & 4.942 & .000 \\
Networking & .112 & .031 & .182 & 2.011 & .013 \\
$\begin{array}{l}\text { School } \\
\text { management }\end{array}$ & .126 & .038 & .128 & 2.009 & .025 \\
support & & & & & \\
\hline
\end{tabular}

From the results displayed in table 3 above, each of the independent variables made significant individual contributions to the prediction of the criterion measure (social justice). The results indicated that the following beta weights represent the predictive strength of the independent variables observed in accordance to the most effective to the least; Acculturation, $\beta=.286, \mathrm{t}=4.942, \mathrm{P}<0.05$; Networking, $\beta=.182, \mathrm{t}=$ 2.011, $\mathrm{P}<0.05$; School management support, $\beta=.128, \mathrm{t}=2.009, \mathrm{P}<0.05$.

\section{Discussion}

The analysis of relationship among between acculturation, school management supports, networking and social justice building among academic staffs as shown in the correlation matrix in table 1 indicates that the correlation coefficients between all the variables were significant. This suggests that, acculturation, school management support, networking could influence social justice building among academic staffs. 
The multiple regression analysis in table 2 shows that acculturation, school management support and networking could influence social justice building among teachers. The magnitude of this relationship in predicting the social justice building among the participants is reflected in the values of coefficient of multiple $\mathrm{R}^{2} .315$ and an adjusted Multiple $\mathrm{R}^{2} .315$ as shown in table 2. Thus, it can be said that $30.9 \%$ of the total variance in the social justice building of the participants is accounted for by the combination of acculturation, school management support and networking. Consequently, the other $69.1 \%$ variation of social justice building could be attributed to factors not included in this study. The F-ratio value of 104.96 significant at 0.05 further affirms this posit that the predictive capacity of the independent variables could not have be attributed to chance factor.

With regard to the extent to which each of the three independent variables contributes to the prediction, as postulated in hypothesis 3 it could be ascertained that acculturation is the most potent predictor of social justice building among the other factors. The finding is corroborated by extant studies of Zane and Mak (2003), Cuellar, Arnold, \& Maldonado (1995) and Rogler, Cortes,\&Malgady (1991). Understanding the cosmopolitan nature of tertiary institutions provides a basis for the recent finding. If individuals show more knowledge of their heritage cultures than they do of the new contact cultures, the model holds that they are less acculturated; similarly, if the persons possess more knowledge of the host cultures, then they are more acculturated. The recognition of intersecting settings and cultures has furthered the theoretical development of the acculturation process. While many processes of change have been identified and described, theory in the area of acculturation is still relatively ineffective at delineating the individual differences in the acculturation experience.

Networking behaviour is the fourth predictor in this study. Extending previous social justice building finding corroborates previous studies. Specifically, these prior studies noted that individuals with a larger social network and with stronger ties in their network reported spending more time on networking during social justice demand, suggesting that network structure is an important determinant of tertiary academic staff's social justice building. A probable explanation is seen from the perspective of a social web which networking is founded on, increasing the potentials and chances of acquiring information about the world of works and demand of rights and fair practices. Also, time spent networking was found to relate positively to number of justice building, and explained additional variance over time spent searching through print advertising, internet, and public services. Thus, teachers who spent more time networking received more concerns for justice building, regardless of their use of other behavioural patterns. This suggests that networking as an informal justice building behaviour provides teachers with information that is nonredundant with information gathered by more formal social 
justice behaviours (Saks \& Ashforth, 2000; Zottoli \& Wanous, 2000).

In this study school management support did not significantly contribute to the prediction of social justice building of teachers. It should be noted that when the quest for fairplay or demands of rights arises, discrepancies always persist between the school management and the staffs or teachers. More so, in addition to some unpalatable policies meted on teachers from the government the school management seems to be of little or no support to the teachers. This might be a plausible reason for the current lack of contribution of school management building to social justice building among teachers.

\section{Recommendations}

1. Academic staffs of tertiary institutions should be encouraged to become more enlightened with acculturation, , networking and management support. It is expected that tertiary academic staffs who can assert self in their academic delivery as well as maintain and regulate their cultural beliefs amongst other beliefs will find it easier to achieve success in their quest for social justice.

2. Teaching values and practices that encourages the development of social justice building, acculturation and networking skills should be encouraged.

3. Policies should be enacted in the country, which will herald and address issues around the social justice building of academic staffs of tertiary institutions.

4. Conferences, seminars, symposiums, workshops should be organized geared at investing and changing positively the perception of social justice building among academic staffs of tertiary institutions.

5. Special agencies should be established with staffs well trained and equipped to effectively manage cases involving social justice as well as synergize the predictor variables in this study to develop adequate training programme to enhance social justice building of academic staffs of tertiary institutions.

\section{Conclusion}

At a time when education is in a constant flux, academic staffs of tertiary institutions are expected to incorporate reforms on a number of levels into their daily practice. This study has shown that social justice building is a necessary factor when considering the teaching profession. Teaching for social justice has the potential to prepare citizens who are sophisticated in their understanding of diversity and group interaction, able to critically evaluate social institutions, and committed to working democratically with diverse others. Occurrences as this has created an environment where those teachers who wish to survive and thrive must become involved in an 
increased rate of personal adaptation and professional development. In order to enhance the social justice building among academic staffs of tertiary institutions, or reduces its economic costs, the following recommendations are hereby made, that, significant stakeholders should utilize for effectiveness.

\section{Reference}

Adams, M., Blumenfeld, W. J., Castandeda, R., Hackman, H. W., Peters, M. L., \& Zuniga, X. (2000). Readings for diversity and social justice. New York: Routledge.

Alexander, R. Jr. (2005). Racism, African Americans, and social justice. New York: Rowman \& Littlefield Publisher.

Balcazar, H., Peterson G.W. \& Krull, J.L. (1997). Acculturation and family cohesiveness in Mexican American pregnant women: social and health implications. Family \& Community Health . 20, 16-31.

Betancourt, H. \& Regeser, S. (1993). The study of culture, ethnicity, and race in American psychology. American Psychology, 48, 629-637.

Bigelow, W., \& Peterson, B. (2002). Rethinking globalization: Teaching for justice in an unjust world. Milwaukee, WI: A Rethinking Schools Publication.

Bigelow, W., Christensen, L., Karp, S., Miner, B., \& Peterson, B. (Eds.). (2000). Rethinking our classroom: Teaching for equity and justice. Milwaukee, WI: A Rethinking Schools Publication.

Collins, P. H. (1998). Fighting words: Black women and the search for justice. Minneapolis: University of Minnesota Press.

Davidov, E., Schmidt, P., \& Schwartz, S. H. (2008). Bringing values back in: The adequacy of the European Social Survey to measure values in 20 countries. Public Opinion Quarterly, 72(3), 420-445.

Delgado, R., \& Stefancic, J. (2001). Critical race theory: an introduction. New York: New York University Press.

Ekanga, B. (2005). Social justice and democracy: The relevance of Rawl's conception of justice in Africa. New York. Peter Lang.

Forret, M. L., \& Dougherty, T. W. (2004). Networking behaviors and career outcomes: Differences for men and women? Journal of Organizational Behavior, 25, $419-437$.

Freire, P. (2003). Pedagogy of the Oppressed. New York: Continuum. 
Frese, M., Fay, D., Hilburger, T., Leng, K., \& Tag, A. (1997). The concept of personal intiative: Operationalization, reliability, and validity in two German samples. Journal of Occupational and Organizational Psychology, 70, 137 161.

Gutstein, E., \& Peterson, B. (Eds.). (2005). Rethinking mathematics: Teaching social justice by the numbers. Milwaukee, WI: Rethinking Schools.

Kennedy, C.M. (2000) Television and young Hispanic children's health behaviors. Pediatric-Nursing. 26, 283-288.

Kim, B. S. K., \& Abreu, J. M. (2001). Acculturation measurement: Theory, current instruments, and future directions. In J. G. Ponterotto, J. M. Casa, L. Suzuki, \& C. M. Alexander (Eds.), Handbook of multicultural counseling (2nd ed., pp. 394 -424). Thousand Oaks, CA: Sage.

Lather, P. (2004). Scientific research in education: A critical perspective. Journal of Curriculum and Supervision, 20(1), 14-30.

Nierenberg, A. R. (2002). Nonstop networking. Hendon, VA: Capital Books

Olesen, V. L. (2000). Feminisms and qualitative research at and into the millennium. In Denzin, N. K. \& Lincoln, Y. S. (Eds.), Handbook of qualitative research (pp. 215-255). Thousand Oaks, CA: Sage Publications.

Padilla, A. M. and Perez, W. (2003). Acculturation, Social Identity, and Social Cognition: A New Perspective. Hispanic Journal of Behavioral Sciences Hispan Journal Behav Science, 25(1):35-55.

Ridley, C.R., Li, L.C. \& Hill, C.L. (1998). Multicultural assessment: reexamination, reconceptualization, and practical application. Counseling Psychologist, 26, 827-911.

Saks, A.M., Ashforth, B.E. (2000). Change in job search behavior and employment outcomes. Journal of Vocational Behavior, 56, 277-287.

Solorzano, D. G., \& Delgado Bernal, D. (2001). Examining transformational resistance through a critical race and LatCrit theory framework: Chicana and Chicano students in an urban context. Urban Education, 36(3), 308-342.

Sturges, J. J. L., Guest, D., Conway, N., \& Davey, K. M. (2002). A longitudinal study of the relationship between career management and organizational commitment among graduates in the first ten years at work. Journal of Organizational Behavior, 23, 731 - 748.

Thompson, J. A. (2005). Proactive personality and job performance: A social capital perspective. Journal of Applied Psychology, 90, 1011 - 1017. 
Torres, N. L. (2005). It's who you know. Entrepreneur, 33, 128 -132

Tyson, C. A. \& Park, S. C. (2006). From theory to practice: Teaching for social justice. Social Studies and the Young Learners, 19(2), 23-25. National Council for the Social Studies.

Tyson, C. A. \& Park, S. C. (2008). Civic education, social justice and Critical Race Theory. In J. Arthur, I. Davies, \& C. Hahn (Eds.). Handbook of education for citizenship and democrary (pp. 29-39). Thousand Oaks: CA, SAGE.

Tyson, C. A. (2002). "Get up offa that thing": African American middle-school students respond to literature to develop a framework for understanding social action. Theory and Research in Social Education, 30(1), 42-65.

Wade, R. C. (2004). Citizenship for social justice. Kappa Delta Pi Record, 40(2), 64 68.

Wirt, J., Choy, S., Rooney, P., Sen, S. P. A., \& Tobin, R. (2005). The condition of education 2004. National Center for Education Statistics.

Witt, P. (2004). Entrepreneurs' networks and the success of start - ups. Entrepreneurship \& Regional Development, 16, 391-412.

Wolff, H.-G., \& Moser, K. (2006). Development and validation of a networking scale. Diagnostica, $52,161-180$

Yi, J.K. (1998). Acculturation and pap smear screening among college-aged Vietnamese women in the United States. Cancer Nursing. 21, 335-341.

Zottoli, M. \& Wanous, J. (2000). Recruitment source research: Current status and future directions. Human Resource Management Review, 10(4), 353-382. 